\title{
A Rapid and Simple Quantitative Method for the Active Ingredients of Aescin in the Extraction Process Using Near Infrared Spectroscopy
}

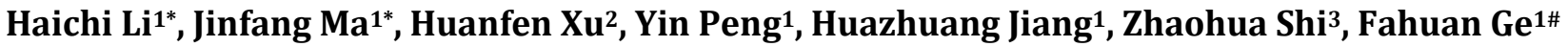 \\ ${ }^{1}$ School of Pharmaceutical Sciences, Sun Yat-Sen University, Guangzhou, China \\ ${ }^{2}$ Guangzhou SonDon Network \& Technology Co., Ltd., Guangzhou, China \\ ${ }^{3}$ Wuhan Aimin Pharmaceutical Co., Ltd., Ezhou, China \\ Email: "gefahuan@mail.sysu.edu.cn
}

How to cite this paper: Li, H.C., Ma, J.F., Xu, H.F., Peng, Y., Jiang, H.Z., Shi, Z.H. and Ge, F.H. (2018) A Rapid and Simple Quantitative Method for the Active Ingredients of Aescin in the Extraction Process Using Near Infrared Spectroscopy. American Journal of Analytical Chemistry, 9, 500-513.

https://doi.org/10.4236/ajac.2018.910037

Received: September 17, 2018

Accepted: October 21, 2018

Published: October 24, 2018

Copyright $\odot 2018$ by authors and Scientific Research Publishing Inc. This work is licensed under the Creative Commons Attribution International License (CC BY 4.0).

http://creativecommons.org/licenses/by/4.0/

\section{c) (i) Open Access}

\begin{abstract}
To achieve a rapid and simple detection for the active ingredients of Aescin in the extraction process using near-infrared spectroscopy (NIR) and to realize the state monitoring and quality control of the extraction process. Partial least square regression (PLS) was applied to build the near-infrared calibration models, and the applicability of the model was investigated by predicting the unknown samples in the extraction process. The correlation coefficients of the established Aescin models (A, B, C, D) were 0.9836, 0.9831, 0.9833, 0.9824 , and the prediction standard deviations (SEP) were $0.05636,0.05043$, $0.02412,0.05636$, respectively. This study suggests that the proposed model has superior stability and accuracy. NIR spectroscopy technique provides a novel efficient and environmentally friendly approach to the rapid determination of four Aescin key quality indicators (A, B, C, D) in the extraction, which was solved the problem that the lack of state monitoring during the extraction of Aescin, thereby improved the quality of Aescin.
\end{abstract}

\section{Keywords}

NIR Spectroscopy, Aescin, Extraction Process, State Monitoring, Quality Control

\section{Introduction}

Aescin is the main active mixture of extract from the seeds of Aesculus chinensis Bunge or Aesculus hippocastanum. Which is a natural compound of acylation

${ }^{\star}$ These authors contributed equally to this work and should be considered co-first authors. 
triterpene glycosides, consisting of A, B, C and D Aescin [1] (Figure 1). Previous studies had proved that Aescin has effective because of its anti-inflammation, antiedema, anti-exudation, and anti-tumor effects, as well as in aiding ischemia injuries and providing blood capillary protection [2]-[7], which is mainly applied in the form of sodium salt to treat diseases such as postoperative edema, phlebitis, haemorrhoids, etc [8]-[16]. However, the lack of simple and rapid quantitative methods in the extraction process of Aesculus chinensis results in low extraction efficiency and may lead to more impurities. At present, the extraction effect is evaluated by HPLC. However, HPLC cannot monitor the extraction process in real time, which may lead to more impurities in the final product.

The stability of the extraction process influences the quality of the Aescin, which severely limit its clinical effect [17] [18] [19] [20]. HPLC has been extensively applied to determine the content of Aescin A-D [16] [21]. In this method, the medicinal material is first subjected to methanol extraction, followed by ungrease treatment with petroleum ether to remove the interfering grease, and then the content of Aescin A-D in extractive can be established by HPLC. The processing step of test solution in this method is complicated and time consuming. In addition, to obtain satisfactory separation degree of component during HPLC, the holding time is relatively long, which cannot meet the requirements of rapid detection of Aesculus chinensis Bunge extractive.

NIR spectroscopy is an environmentally friendly rapid process analysis technology [22] [23], which can realize simultaneous determination of multiple components without requiring pretreatment for samples [24] [25] [26] and has been extensively used in various scientific fields [27]-[36]. Currently, there have been no reports on the application of NIR spectroscopy in quality control during extraction of Aesculus chinensis Bunge. In this study, the extraction process of Aesculus chinensis Bunge medicine material was regarded as research objects. NIRS was adopted to determine the analytical values of Aescin A, B, C, D in Aesculus chinensis Bunge. A rapid and simple quality control method during Aesculus chinensis Bunge extraction process was established using PLS, which is of great research significance and application prospect to quality control during Aesculus chinensis Bunge extraction process.

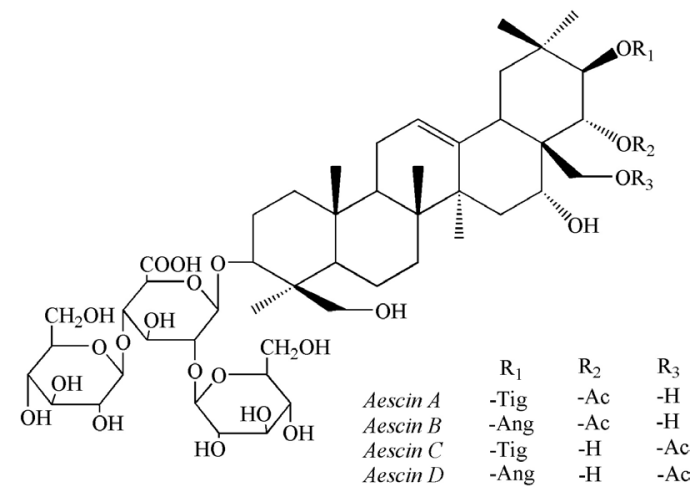

Figure 1. The structure of Aescin [18]. 


\section{Materials and Methods}

\subsection{Materials}

Sodium aescinate as reference substance (National Institutes for Food and Drug Control, batch No.: 100346-200402);

Acetonitrile (chromatographically pure, Merck);

Methyl alcohol (analytically pure, Guangzhou Chemical Reagent Factory);

95\% ethyl alcohol (Pharmaceutical grade, Guangzhou Chemical Reagent Factory).

\subsection{Methods}

\subsubsection{HPLC Method}

The four key quality-indicative ingredients of Aesculus chinensis Bunge were assayed using UltiMate 3000 HPLC instrument (ThermoFisher Scientific Inc., including gradient pump SR-3000, automatic sampler WPS-3000, column thermostat TCC-3000, ultraviolet detector VWD-3100, chromatograph workstation Chameleon 7.2). The chromatographic conditions were set as follows: Kromasil $\mathrm{C}_{18}(4.6 \mathrm{~mm} \times 250 \mathrm{~mm}, 5 \mu \mathrm{m})$ was adopted at a temperature of $30^{\circ} \mathrm{C}$. A isocratic elution program was run at a flow rate of $1.000 \mathrm{~mL} / \mathrm{min}$ using the mobile phase acetonitrile- $0.2 \%$ phosphoric acid solution (36:64). Detecting wavelength was set to $220 \mathrm{~nm}$ for Aescin. The standard and sample solutions were filtered using a $0.45-\mu \mathrm{m}$-milipore filter and $10 \mu \mathrm{L}$ was and subjected to HPLC analysis [37] [38].

\subsubsection{Preparation of Sodium Aescinate as Reference Substance}

$20.40 \mathrm{mg}$ of standard sample of Sodium aescinate was weighed and placed in a $5 \mathrm{~mL}$ volumetric flask, dissolved with $36 \%$ methyl alcohol, and then diluted to constant volume to prepare $1 \mathrm{~mL}$ of stock solution containing $1.5830 \mathrm{mg}$ of Aescin A, $1.1546 \mathrm{mg}$ of Aescin B, $0.5040 \mathrm{mg}$ of Aescin C, $0.3006 \mathrm{mg}$ of Aescin D. Then, using the prepared stock solution, a series of control solutions of different concentrations was prepared.

\subsubsection{Preparation of Extracting Solution}

$3750 \mathrm{ml}$ of $70 \%$ ethyl alcohol was weighed and placed in a $5 \mathrm{~L}$ conical flask, heated to $60^{\circ} \mathrm{C}$ in water bath. Then, $150 \mathrm{~g}$ of Aesculus chinensis Bunge medicine material (smashed and screened by a 60 -mesh sieve). Stirring extraction was performed for $2 \mathrm{~h}, 10 \mathrm{ml}$ of extracting solution was collected every $4 \mathrm{~min}$. A total of 210 samples were collected in 7 batches, the first 70 samples were regarded as modeling set (calibration set), while the remaining 140 samples were regarded as a validation set.

\subsubsection{Sample Measurement}

The extracted solution was filtered by $0.45-\mu \mathrm{m}$-milipore filter, the filtrate and control solution was measured according to chromatographic condition prescribed in section "2.2.1". 


\subsubsection{NIR Spectroscopy Collecting}

NIR spectroscopy for the extracting solution of Aesculus chinensis Bunge was conducted utilizing an NIR spectroscopy instrument (NGD-U10, Guangzhou SonDon Network \& Technology Co., Ltd., Guangzhou, China). The extracting solution of Aesculus chinensis Bunge was placed in a $1 \mathrm{~mm}$ quartz cell. The spectrum scanning was performed with a transmission detector, with scanning wavelength varying between 950 and $1650 \mathrm{~nm}$, scan times of 100, resolution ratio of $2 \mathrm{~nm}$. Each extracting solution was repeatedly scanned for 3 times, and the averaged spectrum was obtained, as showed in Figure 2. The data was processed and calculated using data analysis software Matlab2012a (MathWorks, America).

\section{Results and Discussion}

\subsection{The Standard Curves of Aescin Components}

The working curves were plotted using Aescin concentration as abscissa and peak area as ordinate as showed in Figure 3. The regression equation for Aescin A is $Y=44.861 X-0.0229(r=1.0000)$, linear range was $0.007915-1.5830$ $\mathrm{mg} / \mathrm{mL}$; The regression equation for Aescin B is $Y=36.370 X+0.0094(r=$ 1.0000), linear range was $0.005773-1.1546 \mathrm{mg} / \mathrm{mL}$; The regression equation for Aescin C is $Y=44.943 X-0.0075(r=1.0000)$, linear range was 0.002520 $0.5040 \mathrm{mg} / \mathrm{mL}$; The regression equation for Aescin D is $Y=44.949 X-0.0055(r$ $=1.0000$ ), linear range was $0.001503-0.3006 \mathrm{mg} / \mathrm{mL}$.

\subsection{Establishment of Quantitative Analysis Model of Aescin}

According to the concentrations of Aescin components measured by HPLC, the first 70 samples were regarded as the calibration set, and the calibration model was constructed using PLS; the last 140 samples were regarded as validation set to validate the predictive performance of the calibration model. Concentrations of Aescin components in calibration set and validation set are shown in Table 1. The correlation coefficient $(\mathrm{R})$, root mean square error of cross validation

Table 1. The concentrations of Aescin components in calibration set and validation set.

\begin{tabular}{ccccccc}
\hline Component & Group & $\begin{array}{c}\text { Number of } \\
\text { sample }\end{array}$ & Max value & Min value & Average value & $\begin{array}{c}\text { Standard } \\
\text { deviation }\end{array}$ \\
& Modeling set & 70 & 0.3659 & 0.1162 & 0.2024 & 0.05520 \\
Aescin A & Prediction set & 140 & 0.3016 & 0.1183 & 0.1965 & 0.05484 \\
& Modeling set & 70 & 0.3190 & 0.1009 & 0.1778 & 0.04945 \\
Aescin B & Prediction set & 140 & 0.02689 & 0.1020 & 0.1724 & 0.04917 \\
& Modeling set & 70 & 0.1433 & 0.04263 & 0.07746 & 0.02254 \\
Aescin C & Prediction set & 140 & 0.1191 & 0.04260 & 0.07631 & 0.02295 \\
& Modeling set & 70 & 0.09611 & 0.03068 & 0.05329 & 0.01523 \\
\hline
\end{tabular}




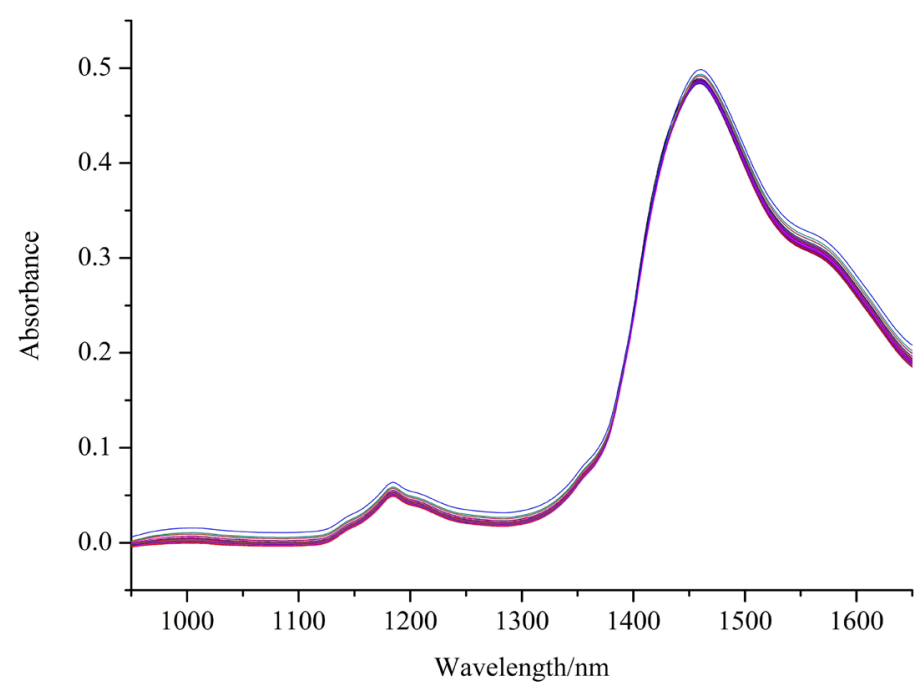

Figure 2. NIR spectroscopy of extracting solution of Aesculus chinensis Bunge.

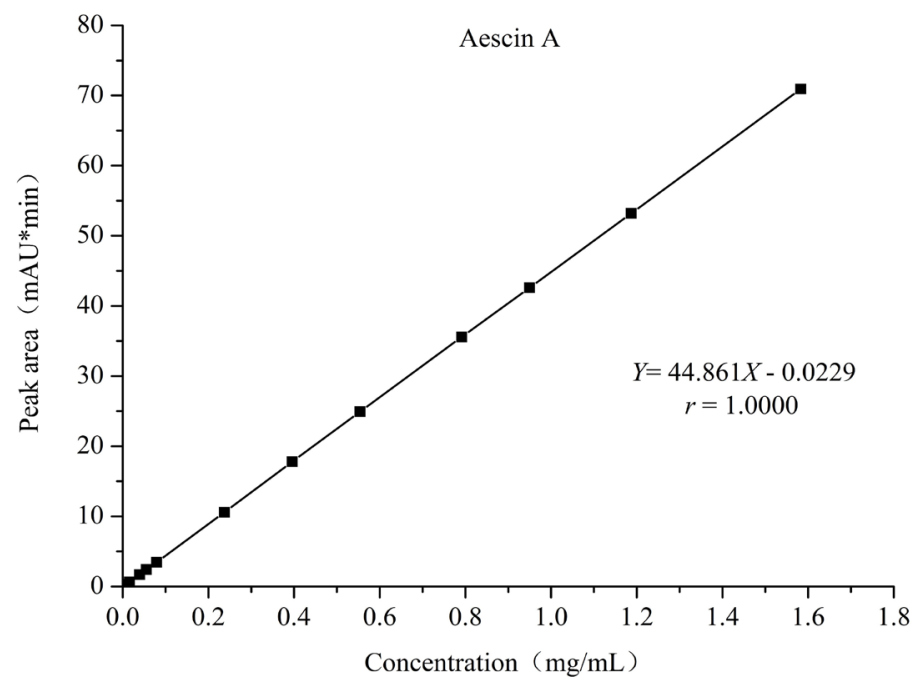

(a)

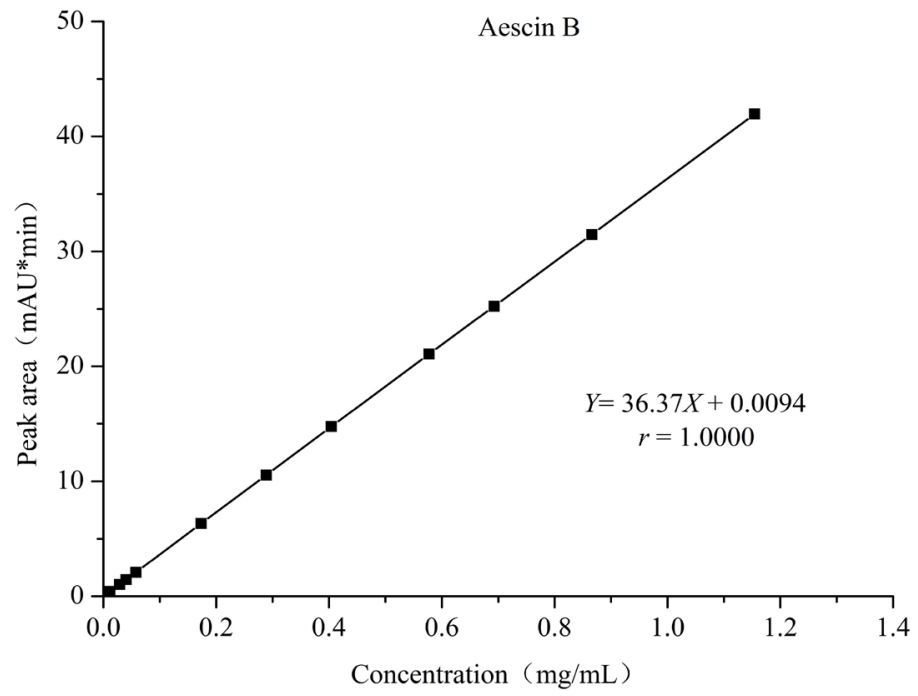

(b) 


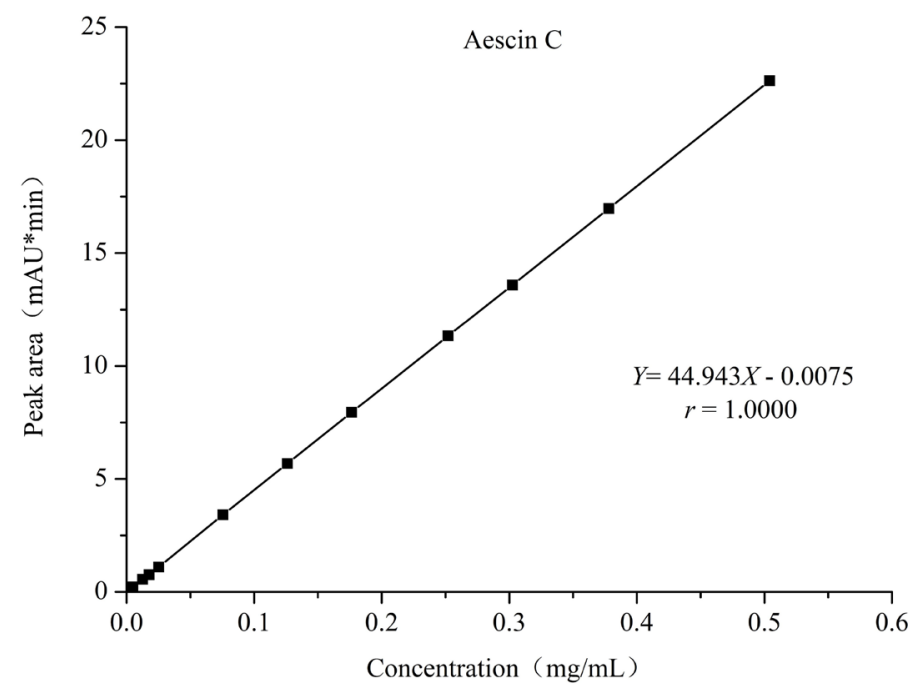

(c)

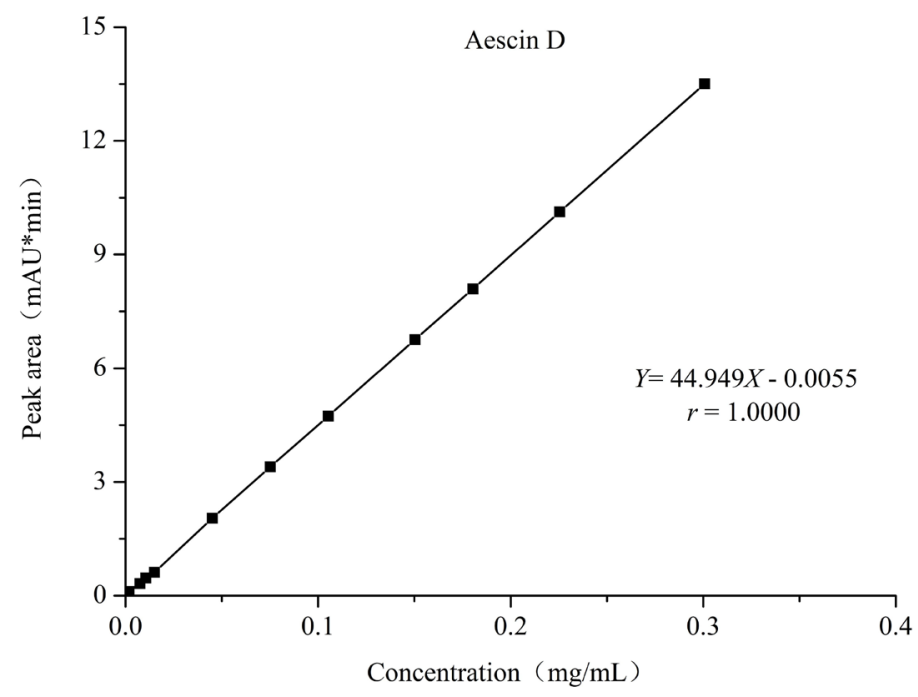

(d)

Figure 3. Standard curves of Aescin components. (a) Aescin A; (b) Aescin B; (c) Aescin C; (d) Aescin D.

(RMSECV), SEP was regarded as evaluation indexes for the model. The larger the $r$ value is, the smaller the RMSECV value is, and the more reasonable the calibration model construction is. The smaller the SEP value is, the better the predictive performance of the model is [39] [40] [41] [42].

\subsection{Selection of the Number of Model Primary Factors}

During modeling construction, the predictive performance of the PLS model is closely related to the number of primary factors (principal components, PCs). In the case that the samples calibration set are given, a too small number of PCs will lead to incomplete information of modeling and reduced predictive performance of model; in contrast, a over-large number of PCs will lead to complex model and introduction of excessive measurement noise, resulting in over-fitting, 
which means that the model suits the calibration set better but reduces the predictive power of the prediction set. Therefore, an appropriate number of PCs is of direct influence on the predictive performance of the model [43] [44] [45]. Every PLS calibration model involves an optimal number of PCs. The RMSECV value varied with the number of PCs, as showed in Figure 4. The minimum RMSECV value corresponds to optimal number of PCs, so the optimal numbers of PCs for Aescin A, Aescin B, Aescin C, Aescin D were 7, 7, 7, 6, respectively.

\subsection{Model Construction and Evaluation}

After sample processing, the near infrared spectra of 70 samples in calibration set were associated with the concentrations of Aescin components (with optimal numbers of primary factors of $7,7,7,6)$ measured by HPLC using PLS within wavelength range of $950 \mathrm{~nm}-1650 \mathrm{~nm}$. The near infrared quantitative calibration models of Aescin A, Aescin B, Aescin C, Aescin D were constructed and analyzed. The correlation coefficients (R) of Aescin A, Aescin B, Aescin C, Aescin D were 0.9836, 0.9831, 0.9833, 0.9824, and RMSECV values were 0.0099, $0.0090,0.0041,0.0029$, respectively. Figure 5 indicates the relation between prediction value and measured value of Aescin components. It can be seen that the $\mathrm{R}$ values of the four key indicators are all greater than $98 \%$, which has a good linear relationship, which means that the NIR spectroscopy has a good prediction effect and can be used for the prediction of the Aescin extraction process. During the modeling process, two exceptional data points (No. 20 and No. 68) were eliminated using automatic optimization function of Software.

\subsection{Prediction Effect and Evaluation}

The near infrared spectra of remaining 140 samples in validation set were input in calibration model to predict the concentration of Aescin components, and the prediction results were compared with the values measured by HPLC to validated the correctness of calibration model, as shown in Figure 6. The RMSECV values of four models were $0.0099,0.0090,0.0041,0.0029$, and their SEP values

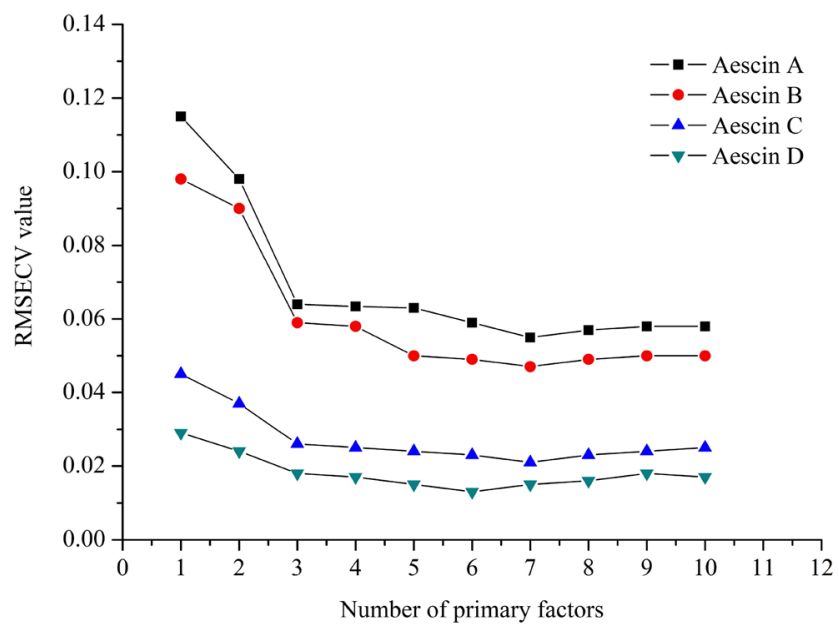

Figure 4. Variation of RMSECV value with number of primary factors. 


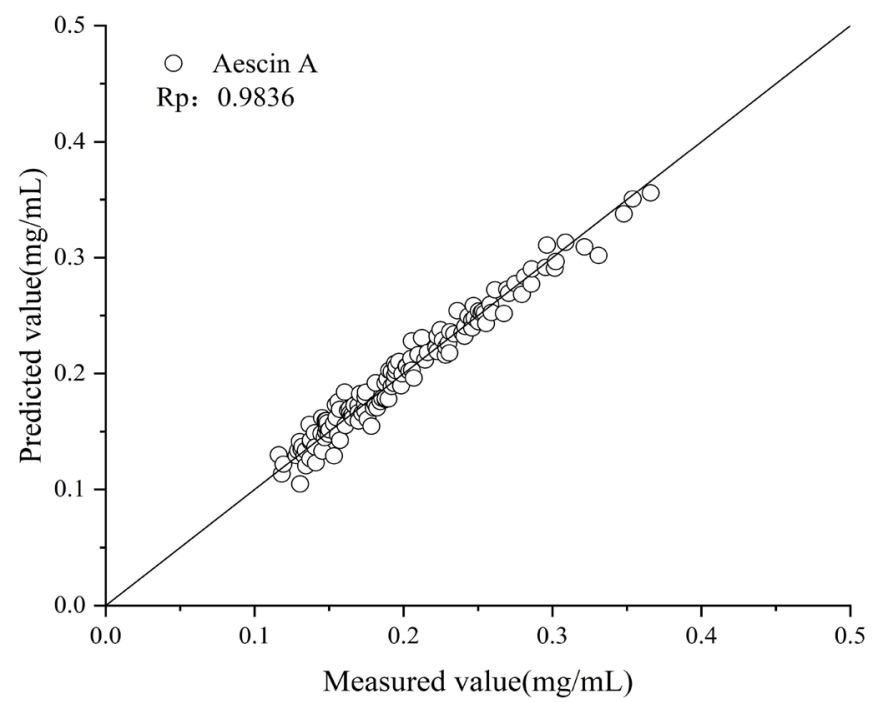

(a)

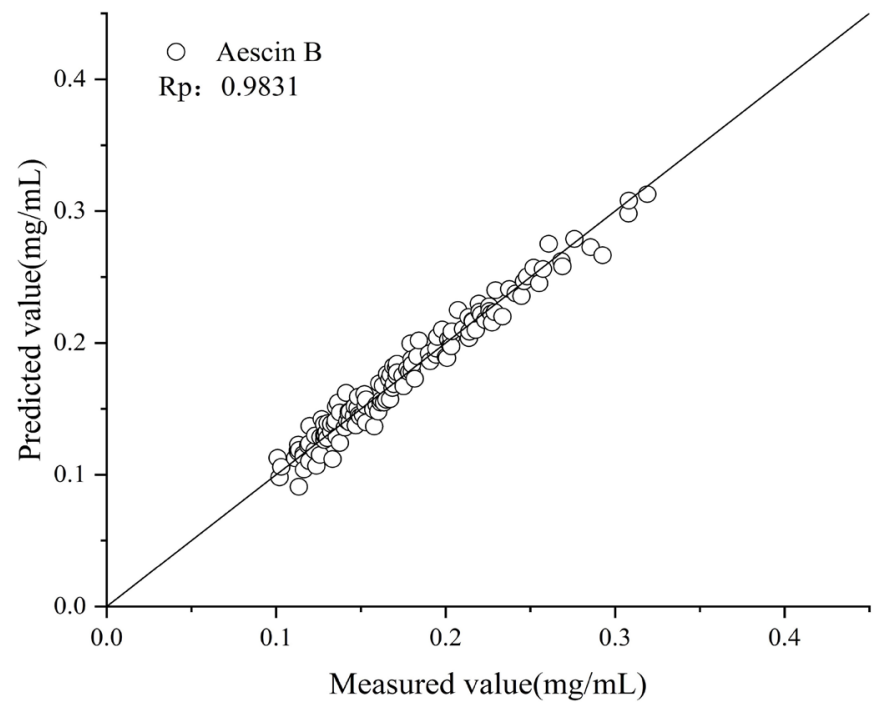

(b)

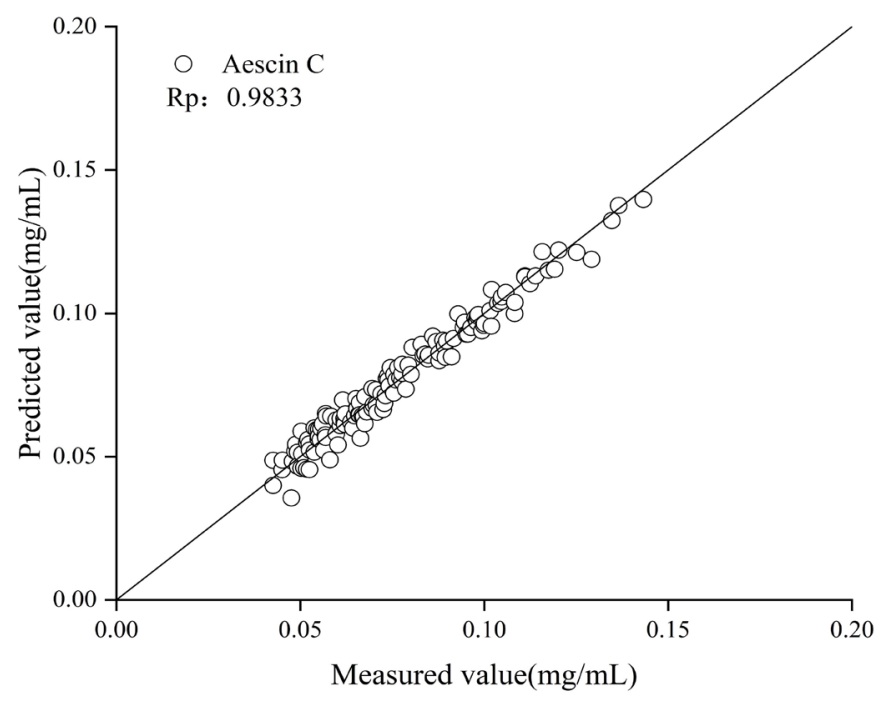

(c) 


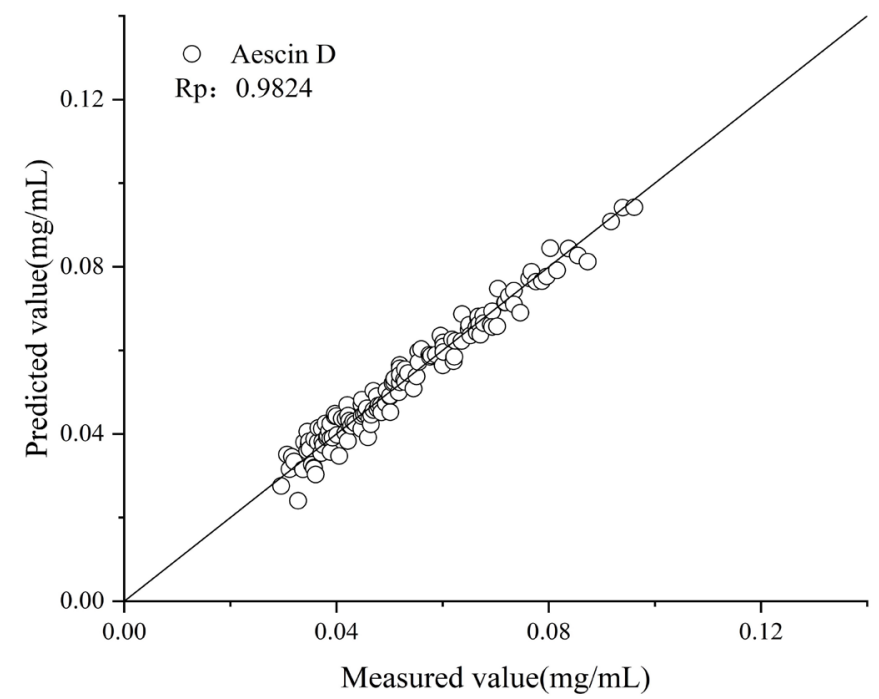

(d)

Figure 5. Relation between prediction value and measured value of Aescin components in calibration set.

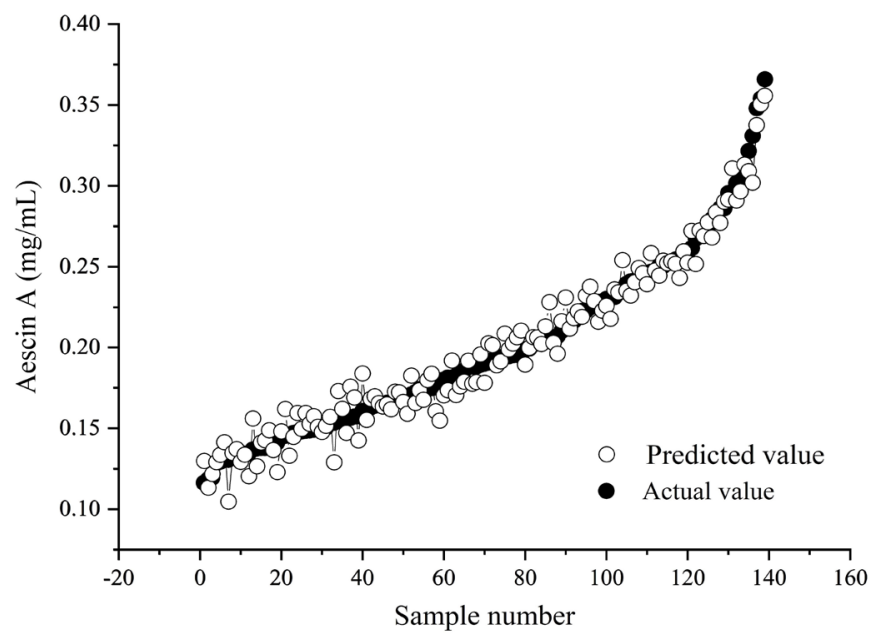

(a)

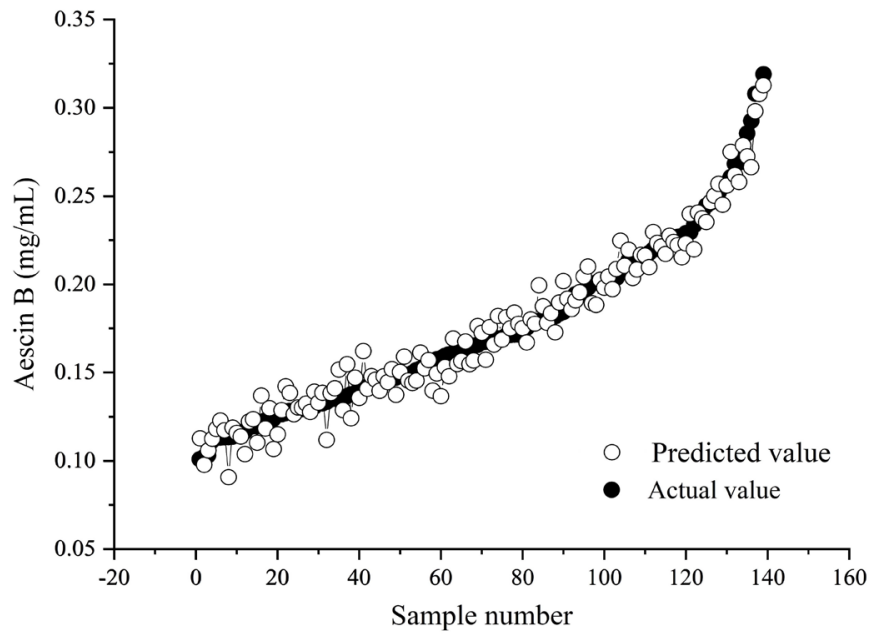

(b) 


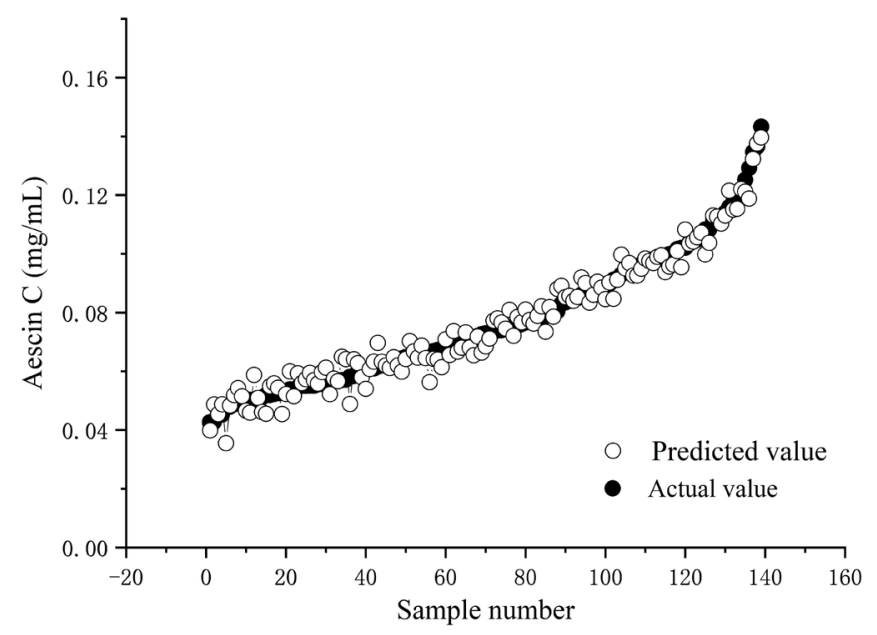

(c)

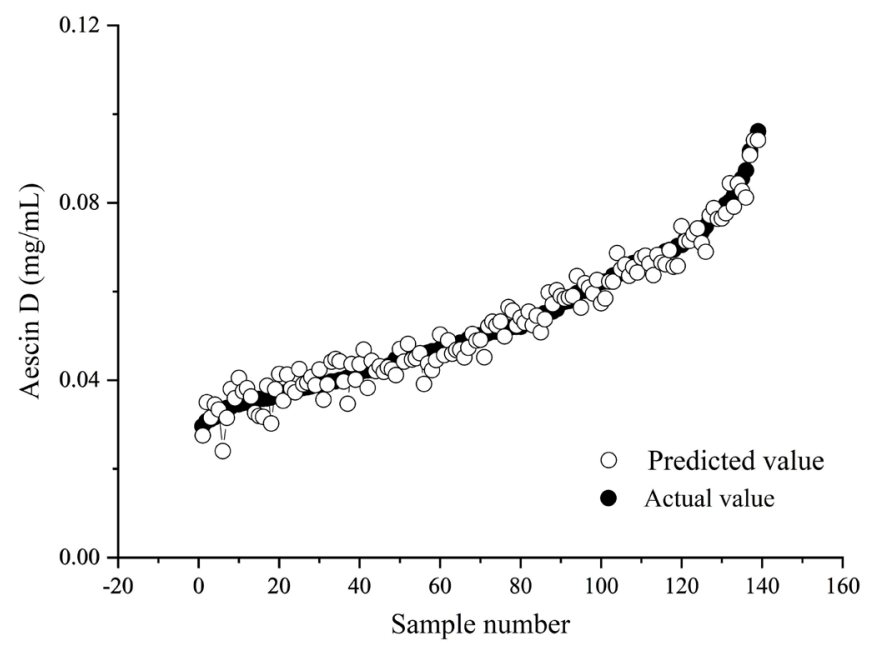

(d)

Figure 6. Relation between prediction value and measured value of Aescin components in validation set.

were $0.05636,0.05043,0.02412,0.01659$, respectively. The correlation coefficients $(\mathrm{R})$ of the four Aescin in the verification set were 0.9790, 0.9759, 0.9783 and 0.9785 , indicating that the prediction results were consistent with the measured values. The model constructed has good prediction ability and can be used for the rapid quantitative analysis of Aescin in the extraction process.

\section{Conclusion}

Regarding the 4 Aescin components in extraction of Aesculus chinensis Bunge, quantitative calibration models were constructed and analyzed using PLS within wavelength range from $950 \mathrm{~nm}$ to $1650 \mathrm{~nm}$. The RMSECV of constructed models were $0.0099,0.0090,0.0041,0.0029$, the $\mathrm{Rp}$ values were $0.9836,0.9831,0.9833$, 0.9824 , and the optimal number of primary factors was set to $7,7,7,6$, respectively. The constructed calibration models were used to predict the concentrations of 4 Aescin components in 140 extracting solution of Aesculus chinensis 
Bunge, and the SEP values were 0.05636, 0.05043, 0.02412, 0.01659, respectively. Using such near infrared method, it only takes $25 \mathrm{~s}$ to measure an extracting solution of Aesculus chinensis Bunge (scanning for 32 times); while it takes at least 50 min to fulfill the same task using the HPLC method. The proposed method is fast, convenient, accurate, without requiring pretreatment for sample, which can be applied to status monitoring and quality control during Aesculus chinensis Bunge extraction and has a great application prospect.

\section{Compliance with Ethical Standards}

\section{Funding}

This study was funded by the National Key R \& D Program of China (2017YFC1703102).

\section{Conflicts of Interest}

The authors declare no conflicts of interest regarding the publication of this paper.

\section{Ethical Approval}

This article does not contain any studies with human participants or animals performed by any of the authors.

\section{References}

[1] Fu, F., Hou, Y., Jiang, W., Wang, R. and Liu, K. (2005) Escin: Inhibiting Inflammation and Promoting Gastrointestinal Transit to Attenuate the Formation of Postoperative Adhesions. World Journal of Surgery, 29, 1614-1620. https://doi.org/10.1007/s00268-005-7870-5

[2] Felipe, M.B.M.C., de Carvalho, F.M., Felix-Silva, J., Fernandes-Pedrosa, M.F., Scortecci, K.C., Agnez-Lima, L.F., et al. (2013) Evaluation of Genotoxic and Antioxidant Activity of an Aesculus hippocastanum L. (Sapindaceae) Phytotherapeutic Agent. Biomedicine \& Preventive Nutrition, 3, 261-266. https://doi.org/10.1016/j.bionut.2012.10.014

[3] Zhao, S.Q., Xu, S.Q., Cheng, J. and Cao, X.L. (2018) Anti-Inflammatory Effect of External Use of Escin on Cutaneous Inflammation: Possible Involvement of Glucocorticoids Receptor. Chinese Journal of Natural Medicines, 16, 105-112. https://doi.org/10.1016/S1875-5364(18)30036-0

[4] Zhang, Z., Cao, G., Sha, L., Wang, D. and Liu, M. (2015) The Efficacy of Sodium Aescinate on Cutaneous Wound Healing in Diabetic Rats. Inflammation, 38 1942-1948. https://doi.org/10.1007/s10753-015-0174-5

[5] Štajner, D., Popović, B.M., Ćalić, D. and Štajner, M. (2014) Comparative Study of Antioxidant Status in Androgenic Embryos of Aesculus hippocastanum and Aesculus flava. Scientific World Journal, 2014, Article ID: 767392. https://doi.org/10.1155/2014/767392

[6] Yu, Z. and Su, P. (2013) Effect of Beta-Aescin Extract from Chinese Buckeye Seed on Chronic Venous Insufficiency. Pharmazie, 68, 428-430.

[7] Xin, W., Zhang, L., Fan, H., Jiang, N., Wang, T. and Fu, F. (2011) Escin Attenuates 
Acute Lung Injury Induced by Endotoxin in Mice. European Journal of Pharmaceutical Sciences, 42, 73-80. https://doi.org/10.1016/j.ejps.2010.10.008

[8] Zhou, X.Y., Fu, F.H., Li, Z., Dong, Q.J., He, J. and Wang, C.H. (2009) Escin, a Natural Mixture of Triterpene Saponins, Exhibits Antitumor Activity against Hepatocellular Carcinoma. Planta Medica, 75, 1580-1585.

https://doi.org/10.1055/s-0029-1185838

[9] Xin, W., Zhang, L., Sun, F., Jiang, N., Fan, H. and Wang, T. (2011) Escin Exerts Synergistic Anti-Inflammatory Effects with Low Doses of Glucocorticoids in Vivo and in Vitro. Phytomedicine, 18, 272-277. https://doi.org/10.1016/j.phymed.2010.08.013

[10] Zhou, X.Y. (2009) Anti-Tumor Activity of Sodium Aescinate and Action Mechanism. Dalian University of Technology, Dalian.

[11] Qi, S.M., Lv, J., Meng, Y., Qi, Z.L. and Ling, L.F. (2015) Role of Sodium Aescinate in Inducing Apoptosis of Human Breast Cancer McF-7 Cells via Inhibiting SRC Activity of AKT, ERK Upstream Signal. China Journal of Chinese Materia Medica, 40, 3267-3272.

[12] Nie, X., Guo, W., Xu, B. and Cui, J.R. (2011) The Antitumor Effect of Sodium Aescinate on Transplantation Tumor of Hepatoma H22 in Mice. Chinese Journal of New Drugs, 20, 688-691.

[13] Deng, Y.Y., Huang, H.N., Wei, G.Y., Huang, H.D., Luo, Q.H., Fu, H.D., et al. (2012) Observation of Efficacy of $\beta$-Sodium Aescinate Combined with Mannitol in Treating Severe Craniocerebral Injury. Chinese General Practice, 15, 2484-2486.

[14] Tian, X.L. (2009) Experimental Research on the Anti-Inflammatory Action of Escin and Its Components A B C D. Journal of Liaoning University of Traditional Chinese Medicine, 11, 175-177.

[15] Zhang, X.F. (2009) Clinical Effect of Sodium Aescinate in Preventing Hematoma after Fracture Operation and Deep Venous Thrombosis. Liaoning Journal of Traditional Chinese Medicine, 40, 1416-1417.

[16] Xiong, Y., Li, H.C., Peng, Y., Ge, F.H. and Shen, X.M. (2016) Latest Research Progress in Aescin Components of Aesculus chinensis Bunge. Journal of Chinese Medicinal Materials, 39, 1195-1199.

[17] Li, S.X., Wang, Y.J., Fan, Y.L., Meng, X.L. and Meng, F.X. (2012) Component Analysis of Aesculus chinensis Bunge during Growing Period. Qilu Pharmaceutical Affairs, 31, 147-148.

[18] Shi, Z.H., Guan, X.Y., Zhang, Y.J., Chen, K.L., Ye, L.C. and Zheng, G.H. (2013) Chemical Quality of Aesculus chinensis Bunge. Chinese Journal of Experimental Traditional Medical Formulae, 13, 144-147.

[19] Shi, Z.H., Xie, C.X., Guang, X.Y., Chen, L.J., Ye, L.C. and Liu, X.P. (2013) Research on Ecological Adaptability of the Source Area of Aesculus chinensis Bunge. Modern Chinese Medicine, 15, 303-307.

[20] Du, W.J., Shi, Z.H., Ye, L.C., Li, Q., Guan, X.Y. and Mei, Z.N. (2018) Textual Research of Aesculus chinensis Bunge. Chinese Patent Medicine, 40, 425-428.

[21] Shi, Z.H., Ye, L.C., Guan, X.Y., Du, W.J., Zhang, X.C. and Mei, Z.N. (2018) Construction of Chromatographic Fingerprint of Aesculus chinensis Bunge and Its Application in Medicinal Material Identification. Chinese Journal of Experimental Traditional Medical Formulae, 24, 41-45.

[22] Pasquini, C. (2018) Near Infrared Spectroscopy: A Mature Analytical Technique with New Perspectives-A Review. Analytica Chimica Acta, 1026, 8-36. 
https://doi.org/10.1016/j.aca.2018.04.004

[23] Feng, J.W. and Gao, J.F. (1998) Application of Near Infrared Spectroscopy in the Pharmaceuticals Industry. Chinese Pharmaceutical Journal, 33, 497-498.

[24] Lu, W.Z., Yuan, H.F., Xu, G.T. and Qiang, D.M. (2000) Modern near Infrared Spectroscopic Techniques. China Petrochemical Press, Beijing.

[25] Ruan, Z.G. and Li, B. (2011) Principle of near Infrared Spectroscopy and Its Application in Traditional Chinese Medicinal Materials. Chinese Journal of Pharmaceutical Analysis, 31, 408-416.

[26] Yang, Y., Wang, L., Wu, Y., Liu, X., Bi, Y., Xiao, W., et al. (2017) On-Line Monitoring of the Extraction Process of Flos Lonicerae Japonicae Using near Infrared Spectroscopy Combined with Synergy Interval PLS and Genetic Algorithm. Spectrochimica Acta Part A: Molecular and Biomolecular Spectroscopy, 182, 73-80. https://doi.org/10.1016/j.saa.2017.04.004

[27] Cai, Y.H. and Tan, K.Z. (2007) Determination of Fatty Acid Content in Soybean Based on near Infrared Spectroscopy. Transactions of the Chinese Society of Agricultural Engineering, 23, 238-241.

[28] Wang, X.F., Ma, B.F., Shi, L., Deng, D.W. and Geng, X. (2013) Determination of Coarse Fibre Content in Fodder Using near Infrared Spectroscopy. Science and Technology of Food Industry, 34, 75-77.

[29] Tabasi, S.H., Moolchandani, V., Fahmy, R. and Hoag, S.W. (2009) Sustained Release Dosage Forms Dissolution Behavior Prediction: A Study of Matrix Tablets Using NIR Spectroscopy. International Journal of Pharmaceutics, 382, 1-6. https://doi.org/10.1016/j.ijpharm.2009.07.029

[30] Zhu, J.Q., Pan, W.F., Zhong, Y., Fan, X.H., Kang, L.Y. and Li, Z. (2014) Dynamic Prediction Model for the Extraction Process of Red Ginseng Based on near Infrared Spectrum. China Journal of Chinese Materia Medica, 39, 2660-2664.

[31] Xu, C.Y., Ye, Z.L., Li, D.K., Zhou, D.Z. and Liu, J.D. (2014) Rapid Determination of Contents of Naringin and Neohesperidin in Fructus aurantii Extracting Solution Using near Infrared Transmission Spectroscopy. Chinese Journal of Experimental Traditional Medical Formulae, 20, 86-90.

[32] Zhao, Z.Z. and Liang, Z.T. (2012) Application of near Infrared Spectroscopy in TCD Identification and Relevant Advantages. China Journal of Chinese Materia Medica, 37, 1062-1065.

[33] Li, W.Y., Bagnol, L., Berman, M., Chiarella, R.A. and Gerber, M. (2009) Application of NIR in Early Stage Formulation Development. Part II. Content Uniformity Evaluation of Low Dose Tablets by Principle Component Analysis. International Journal of Pharmaceutics, 380, 49-54. https://doi.org/10.1016/j.ijpharm.2009.06.032

[34] Wenz, J.J. (2018) Examining Water in Model Membranes by near Infrared Spectroscopy and Multivariate Analysis. Biochimica et Biophysica Acta (BBA)Biomembranes, 1860, 673-682. https://doi.org/10.1016/j.bbamem.2017.12.007

[35] Sampaio, P., Soares, A., Castanho, A., Almeida, A.S., Oliveira, J. and Brites, C. (2017) Dataset of Near-Infrared Spectroscopy Measurement for Amylose Determination Using PLS Algorithms. Data in Brief, 15, 389-396. https://doi.org/10.1016/j.dib.2017.09.077

[36] Cayuela, J.A. and García, J.F. (2018) Nondestructive Measurement of Squalene in Olive Oil by near Infrared Spectroscopy. LWT-Food Science and Technology, 88, 103-108. https://doi.org/10.1016/j.lwt.2017.09.047

[37] Chinese Pharmacopoeia Commission (2015) Pharmacopoeia of the People's Repub- 
lic of China. Vol.1, China Medical Science Press, Beijing, 292-293.

[38] Chen, J., Li, W., Yang, B., Guo, X., Lee, F.S. and Wang, X. (2007) Determination of Four Major Saponins in the Seeds of Aesculus chinensis Bunge Using Accelerated Solvent Extraction Followed by High-Performance Liquid Chromatography and Electrospray-Time of Flight Mass Spectrometry. Analytica Chimica Acta, 596, 273-280. https://doi.org/10.1016/j.aca.2007.06.011

[39] Genisheva, Z., Quintelas, C., Mesquita, D.P., Ferreira, E.C., Oliveira, J.M. and Amaral, A.L. (2018) New PLS Analysis Approach to Wine Volatile Compounds Characterization by near Infrared Spectroscopy (NIR). Food Chemistry, 246, 172-178. https://doi.org/10.1016/j.foodchem.2017.11.015

[40] Schlegel, L.B., Schubert-Zsilavecz, M. and Abdel-Tawab, M. (2017) Quantification of Active Ingredients in Semi-Solid Pharmaceutical Formulations by near Infrared Spectroscopy. Journal of Pharmaceutical and Biomedical Analysis, 142, 178-189. https://doi.org/10.1016/j.jpba.2017.04.048

[41] Tao, L., Lin, Z., Chen, J., Wu, Y. and Liu, X. (2017) Mid-Infrared and Near-Infrared Spectroscopy for Rapid Detection of Gardeniae Fructus by a Liquid-Liquid Extraction Process. Journal of Pharmaceutical and Biomedical Analysis, 145, 1-9. https://doi.org/10.1016/j.jpba.2017.06.021

[42] Liu, R., Sun, Q., Hu, T., Li, L., Nie, L., Wang, J., et al. (2018) Multi-Parameters Monitoring during Traditional Chinese Medicine Concentration Process with near Infrared Spectroscopy and Chemometrics. Spectrochimica Acta Part A: Molecular and Biomolecular Spectroscopy, 192, 75-81. https://doi.org/10.1016/j.saa.2017.10.068

[43] Rébufa, C., Pany, I. and Bombarda, I. (2018) NIR Spectroscopy for the Quality Control of Moringa oleifera (Lam.) Leaf Powders: Prediction of Minerals, Protein and Moisture Contents. Food Chemistry, 261, 311-321.

https://doi.org/10.1016/j.foodchem.2018.04.066

[44] Li, Y.K. and Jing, J. (2014) A Consensus PLS Method Based on Diverse Wavelength Variables Models for Analysis of Near-Infrared Spectra. Chemometrics and Intelligent Laboratory Systems, 130, 45-49. https://doi.org/10.1016/j.chemolab.2013.10.005

[45] Pan, W.J., Ma, J.F., Xiao, X., Huang, Z.W., Zhou, H.B., Ge, F.H., et al. (2017) Near-Infrared Spectroscopy Assay of Key Quality-Indicative Ingredients of Tongkang Tablets. AAPS PharmSciTech, 18, 913-919.

https://doi.org/10.1208/s12249-016-0562-7 